\title{
CROSS-BORDER SURVEILLANCE DIFFERENCES: TICK-BORNE ENCEPHALITIS AND LYME BORRELIOSIS IN THE CZECH REPUBLIC AND POLAND, 1999-2008
}

\author{
Paweł Stefanoffi', Hana Orlíková2, Vladimír Príkazský2, Čestmír Beneš², Magdalena Rosińska ${ }^{1}$ \\ ${ }^{1}$ National Institute of Public Health - National Institute of Hygiene, Warsaw, Poland \\ ${ }^{2}$ National Institute of Public Health, Prague, Czech Republic
}

\begin{abstract}
SUMMARY
We compared neighbouring regions of the Czech Republic $(\mathrm{CZ})$ and Poland $(\mathrm{PL})$ situated within $100 \mathrm{~km}$ of the country border, in order to compare surveillance systems performance in measuring the burden of tick-borne diseases in both countries. We used routine surveillance notifications from 1999-2008 on tick-borne encephalitis (TBE) and Lyme borreliosis (LB). We assessed the crude risk ratio (RR) across the country border, and its estimates adjusted for both population density and the expected epidemiological gradient across the region, using negative binomial regression. The crude RR between $\mathrm{CZ}$ and PL was 7.43 (95\% Cl 6.20-8.90) for TBE, and 1.80 (1.76-1.83) for LB. The adjusted RR for TBE increased from 4.47 in 1999-2001 to 10.01 in 2005-2008, but for LB decreased from 9.30 to 2.51 during the respective periods. Those results reflect possible differences in surveillance systems performance between the two countries, as the administrative boundaries cannot constitute a barrier for zoonotic diseases and no biological processes alone can explain such large differences in disease occurrence.
\end{abstract}

Key words: Lyme borreliosis, tick-borne encephalitis, surveillance, cross-border

Address for correspondence: H. Orlíková, Department of Infectious Diseases Epidemiology, CEM, National Institute of Public Health, Šrobárova 48, 10042 Prague 10, Czech Republic. E-mail: horlikova@szu.cz

\section{INTRODUCTION}

Public health surveillance is the ongoing, systematic collection, analysis, interpretation, and dissemination of data regarding a health-related event for use in public health action to reduce morbidity and mortality and to improve health (1). Data generated by public health surveillance systems are often used for long term programme planning and evaluation as well as for travel advice. Therefore, information on disease burden should be recorded in a compatible way across administrative entities.

There is increasing interest in studying the influence of administrative borders, most often associated with real cultural and linguistic boundaries, socio-demographic compartmentalisation, differences in land use as well as topographical features on disease spread, healthcare utilization or ability to respond to public health emergencies (2-4). In the European Union, where unrestricted movement of people and goods is assured between Member States, political borders no longer constitute an important barrier for the spread of infectious diseases. During the past decade, the European Community and the European Centre for Disease Prevention and Control (ECDC) have made considerable efforts to collect surveillance information from all European Union Member States, and standardize the information at European level through implementation of common case definitions $(5,6)$. However, there is an increasing understanding that when comparing data from different countries, other factors such as the degree of underreporting, diagnostic capacity and utilization of healthcare resources may impact the assessment of the burden of illness in the population. These factors are not usually considered in international reports, which rely on estimates of underreporting obtained by different methods provided by countries $(7,8)$.

In this investigation we explore the potential usefulness of aligning data from cross border neighbouring areas for rapid evaluation of surveillance systems outcomes. We used the example of two tick-borne diseases: tick-borne encephalitis (TBE) and Lyme borreliosis (LB) surveillance in the Czech Republic and Poland. Both diseases are endemic in these Central European countries, as documented by communicable disease surveillance and field studies (9-13). As both countries have similar public health systems, originating from the Soviet Union dictated model of uniform, centralized structures, it is often assumed that both systems should measure the disease occurrence with compatible performance. A similar cross-border gradient approach was used a few times in studying socio-economical determinants of diseases, assessing whether living in neighbouring urban areas (14) or being member of the same ethnic minority in neighbouring towns in two countries (15) is associated with differences in health indicators. 


\section{MATERIALS AND METHODS}

\section{Study Area}

We selected neighbouring administrative districts in the Czech Republic (CZ) and Poland (PL), located within approximately $100 \mathrm{~km}$ of the country border. We decided to include this area based on the assumption that determinants of tick-borne disease risk should not differ in a small region, where no natural barriers exist limiting the free movement of animals and people. The selected area consists of 24 districts in CZ and 51 districts in PL (Fig. 1). The two studied regions were different in terms of average district area and population density (Table 1). The area selected in CZ comprised larger, but less densely populated districts, whereas the area selected in PL had more industrialized, densely populated districts.

\section{Surveillance Systems Organization}

In both CZ and PL notification of these diseases was mandatory (in CZ LB since 1986, TBE since 1965; in PL LB since 1998, TBE since 1970). Following the diagnosis of a case, the physician notifies the district public health authority. District public health officers complete standardized case reports based on medical documentation and direct interview with the patient. In $\mathrm{CZ}$, district public health officers enter the case reports into an electronic database, and transfer weekly to the regional public health offices. Regional officers forward the data to the National Institute of Public Health in Prague (NIPH). In PL, district public health officers send biweekly reports on the number of incident cases to provincial offices. Regional officers send reports aggregated at regional level to the National Institute of Public Health-National Institute of Hygiene in Warsaw (NIPH-NIH).

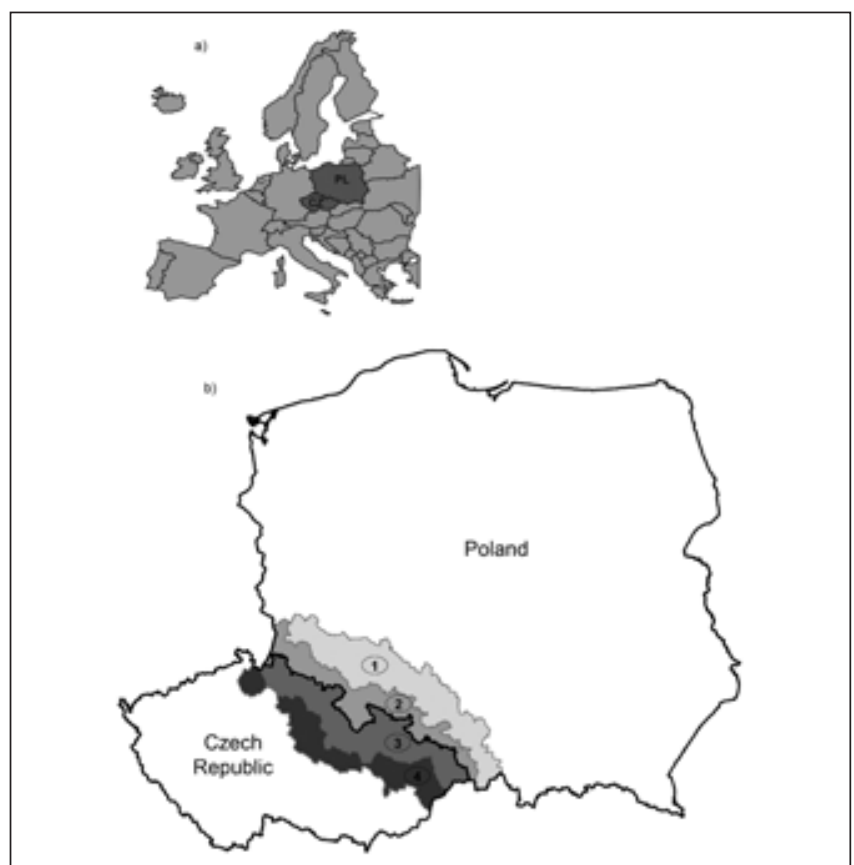

Fig. 1 a) Location of the Czech Republic and Poland on the map of Europe, b) Cross-border CZ-PL study area situated $100 \mathrm{~km}$ along the country border divided into 4 zones aligned from north-east to south-west.
Table 1. Demographic and surveillance characteristics of selected cross-border region, the Czech Republic and Poland, 1999-2008

\begin{tabular}{|c|c|c|}
\hline & Czech $^{*}$ & Poland** \\
\hline \multicolumn{3}{|l|}{ District characteristics } \\
\hline Number & 24 & 51 \\
\hline Mean area $\left(\mathrm{km}^{2}\right)$ & 965 & 520 \\
\hline Mean district population (1999-2008) & 140,904 & 117,926 \\
\hline Total study area $\left(\mathrm{km}^{2}\right)$ & 23,160 & 26,496 \\
\hline Total population & $3,096,060$ & $6,014,220$ \\
\hline Population density (inhabitants $/ \mathrm{km}^{2}$ ) & 133.6 & 227.0 \\
\hline \multicolumn{3}{|l|}{ Surveillance characteristics } \\
\hline Number of Health Departments & 24 & 36 \\
\hline Number of mandatory notifiable diseases & 200 & 72 \\
\hline Number of physicians per 10,000 inhabitants & 35.6 & 26.9 \\
\hline
\end{tabular}

*Data from the Czech Statistical Office (16)

${ }^{* *}$ Data from the Central Statistical Office of Poland (17)

Every 3 months, district public health officers send individual case reports including demographic, clinical and epidemiological information to NIPH-NIH, where they are processed. In both countries feedback on the number of incident cases is provided on the Institutes websites $(18,19,20)$.

\section{Case Definitions}

CZ and PL implemented the surveillance case definitions for both tick-borne diseases in 2005 and 2008, respectively. Since they were not used in the surveillance systems in the two countries during most of the analyzed years (1999-2008), and therefore some key information may not have been recorded for each case, we decided to include in the present analysis all cases notified by physicians. We referred cases to the district of residence. To address concerns regarding the possibility of different diagnosis of reported cases, we verified that more than $95 \%$ of reported TBE cases were confirmed serologically in both countries, and more than $85 \%$ of LB cases reported in CZ and $70 \%$ cases reported in PL met criteria for confirmed case (either Erythema Migrans diagnosed by a physician or late phase confirmed by appropriate laboratory investigation).

\section{Statistical Analysis}

We calculated incidence as the number of reported cases per 100,000 population in given year and district. We divided the region into near border zones (districts with country border) and the zones distant from the border, thus creating 4 zones aligned from north-east to south-west (Fig. 1b). We computed the risk ratios (RRs) between countries, and between adjacent zones (zone 4 vs. 3, 3 vs. 2 and 2 vs. 1, south-west vs. north-east) to see if the difference between CZ and PL to a certain degree might be explained by natural epidemiological gradient of the disease when moving from south-west to north-east. Should the gradient explain the differences between countries we expected similar RRs for all three comparisons. We used Mantel-Haenszel test for homogeneity of risk ratios in stratified analysis. Negative binomial regression was used with annual incidence as an outcome variable 
to adjust the risk ratio across border for expected epidemiological gradient (measured by zone number as numerical variable), calendar period and population density in the area accounting for overdispersion in the data. All analyses were performed using SAS software v. 9.1.

\section{RESULTS}

\section{Data on Tick-borne Diseases}

During 1999-2008, 1,151 TBE cases and 12,335 LB cases were notified in the cross-border region of the Czech Republic. In contrast, $108 \mathrm{TBE}$ cases and 6,783 LB cases were notified in the neighbouring area in Poland. Between 1999 and 2008, CZ experienced a nearly 2-fold increase in tick-borne disease incidence; LB incidence increased from 23.6 to 46.5 cases per 100,000 inhabitants, and TBE incidence increased from 2.5 to 4.2 cases per 100,000 inhabitants (Fig. 2). In PL, LB incidence increased from 1.0 to 25.2 cases per 100,000 inhabitants, and TBE incidence varied from 0.1 to 0.4 cases per 100,000 inhabitants (Fig. 2).

\section{Differences in Tick-borne Disease Geographical Distribution in the Studied Area}

During the studied period, high TBE incidence was reported in several CZ districts each year (Fig. 3). In PL cases were noted in districts adjacent to the border suggesting continuation of the same foci, but with much smaller intensity (Fig. 3). Especially

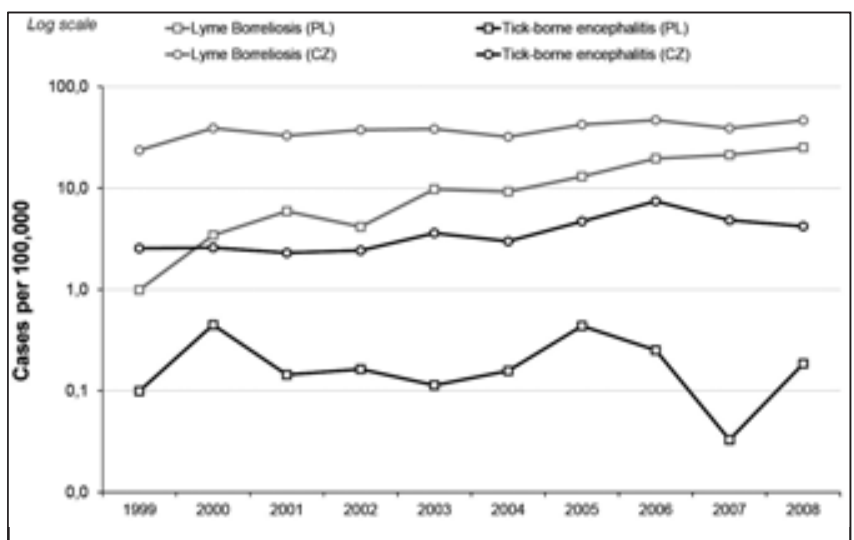

Fig. 2. Graph of reported incidence of TBE and LB per 100,000 population in the Czech Republic and Polish part of the crossborder CZ-PL study area during period 1999-2008.

in 2006, when CZ notified the historical peak of TBE incidence (11), there was no corresponding incidence increase in PL (Fig. 2) and in some areas the disease was stopping sharply at the country border (Fig. 3). The observed crude risk ratio between $\mathrm{CZ}$ and PL was 7.43 (95\% CI 6.20-8.90) (Table 2). When comparing the expected incidence gradient in both countries, we obtained a gradient of increasing TBE incidence towards the south-west, comparable in CZ and PL (p-value for difference between CZ and PL: 0.26) (Table 2). In the multivariable analysis RR between CZ and PL adjusted for the epidemiological gradient and population density was 4.47 (95\% CI 2.35-8.53) in 1999-2001 and increased to 10.01 (95\% CI 5.48-18.28) in 2005-2008 (Table 3).

Table 2. Crude risk ratios from Mantel-Hanszel analysis, cross-border region in the Czech Republic and Poland, 1999-2008

\begin{tabular}{|l|c|c|c|c|c|c|}
\hline \multirow{2}{*}{} & \multicolumn{3}{|c|}{ Tick-borne encephalitis } & \multicolumn{3}{|c|}{ Lyme borreliosis } \\
\cline { 2 - 7 } & RR & $95 \%$ Cl & p value* & RR & $95 \%$ Cl & p value* \\
\hline Country (CZ vs. PL) & 7.43 & $6.20-8.90$ & NA & 1.82 & $1.78-1.85$ & NA \\
\hline Districts with country border (CZ vs. PL) & 7.03 & $5.17-9.55$ & NA & 2.17 & $2.08-2.26$ & NA \\
\hline Gradient from south-west to north-east in PL & 1.55 & $1.04-2.30$ & 0.2555 & 1.05 & $0.99-1.11$ & 0.0029 \\
\hline Gradient from south-west to north-east in CZ & 1.22 & $1.09-1.37$ & & 0.95 & $0.92-0.98$ & \\
\hline
\end{tabular}

${ }^{*} \mathrm{p}$-value for difference between strata; RR - risk ratio; $\mathrm{Cl}$ - confidence interval; NA - not available

Table 3. Risk ratios adjusted for surveillance period and population density of the studied districts, cross-border region in the Czech Republic and Poland, 1999-2008

\begin{tabular}{|c|c|c|c|c|c|c|}
\hline & \multicolumn{3}{|c|}{ Tick-borne encephalitis } & \multicolumn{3}{|c|}{ Lyme borreliosis } \\
\hline & aRR & $95 \% \mathrm{Cl}$ & $p$ value* & aRR & $95 \% \mathrm{Cl}$ & $p$ value* \\
\hline \multicolumn{7}{|l|}{ Country by period (CZ vs. PL): } \\
\hline Country in 1999-2001 & 4.47 & $2.35-8.53$ & $<0.001$ & 9.30 & $6.66-12.97$ & $<0.001$ \\
\hline Country in 2002-2004 & 8.18 & $4.12-16.23$ & $<0.001$ & 4.54 & $3.25-6.36$ & $<0.001$ \\
\hline Country in 2005-2008 & 10.01 & $5.48-18.28$ & $<0.001$ & 2.51 & $1.85-3.43$ & $<0.001$ \\
\hline Gradient from south-west to north-east ${ }^{\#}$ & 1.44 & $1.15-1.81$ & 0.001 & 0.99 & $0.88-1.12$ & 0.927 \\
\hline \multicolumn{7}{|c|}{ Population density of districts (reference: $\geq 500$ inhabitants $/ \mathrm{km}^{2}$ ) } \\
\hline$<100$ inhabitants $/ \mathrm{km}^{2}$ & 4.36 & $2.97-6.41$ & $<0.001$ & 1.21 & $1.02-1.44$ & 0.031 \\
\hline 100-499 inhabitants/km² & 1.89 & $1.33-2.71$ & $<0.001$ & 1.14 & $0.98-1.31$ & 0.082 \\
\hline
\end{tabular}

*Wald test; $\mathrm{Cl}$ - confidence interval; aRR - adjusted risk ratio; parameter alpha for TBE model 0.76, for LB model 0.52.

\#zone number entered as numerical (score) variable 


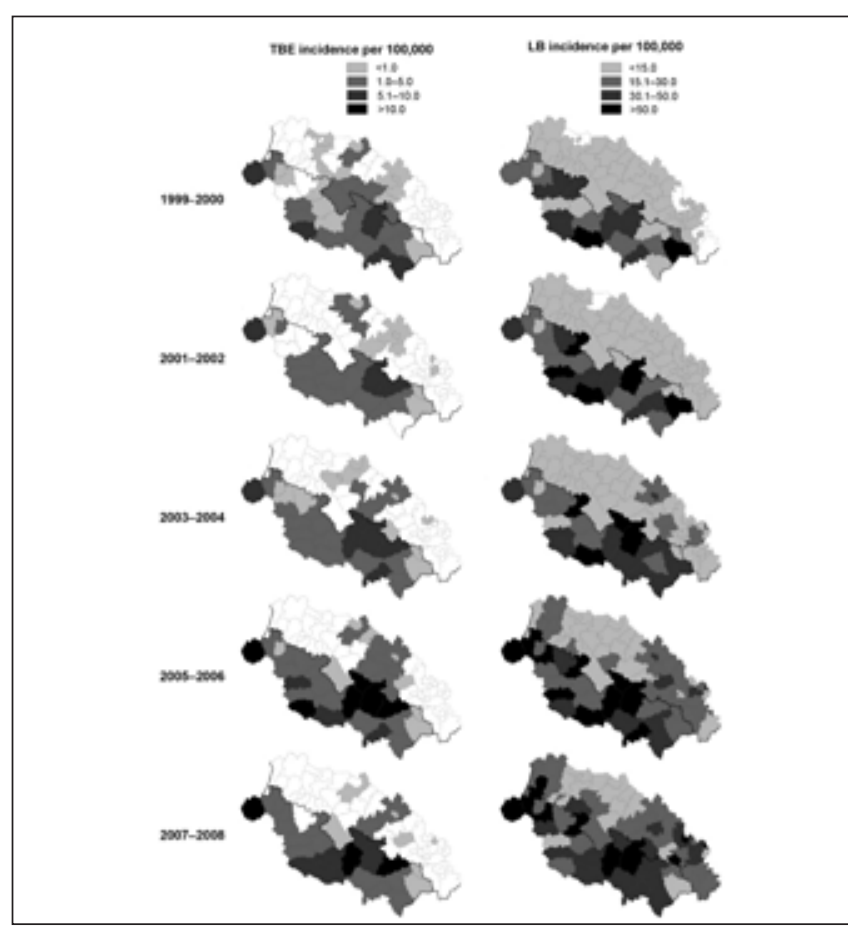

Fig. 3. Choropleth maps with distribution of TBE and LB incidence, respectively, per 100,000 population in the cross-border CZ-PL study area in five periods 1999-2000, 2001-2002, 2003-2004, 2005-2006, 2007-2008.

In contrast, LB was characterized by a relatively uniform spatial distribution of the disease across the 10-year period (Fig. 3). However, a clear incidence step across the border could be observed, documented by the crude RR between CZ and PL of 1.82 (95\% CI 1.78-1.85) (Table 2). The difference was even more pronounced $(\mathrm{RR}=2.17)$ when restricting the analysis to the near border zone. There was no clear epidemiological north-east to south-west LB incidence gradient (Table 2). RR adjusted for epidemiological gradient and district population density decreased from 9.30 (95\% CI 6.66-12.97) in 1999-2001 to 2.51 (95\% CI 1.85-3.43) in 2005-2008 (Table 3).

\section{DISCUSSION}

There are numerous barriers which can limit the spread of vector-borne diseases, but political borders do not belong to them. Under this assumption, we propose a simple method for comparison of surveillance outcomes in neighbouring countries or regions. This method could be easily applied to gain insight into the validity of burden of illness comparisons based on surveillance data originating from two or more autonomous systems. It may be useful especially in regions where resources are lacking for application of sophisticated tools for burden of illness estimation, such as modelling, serologic survey data or large-scale studies of animal reservoir.

We applied our comparison using the example of two tickborne diseases: TBE, which usually occurs in limited foci and LB, typically evenly distributed across large areas in Europe $(10,13)$. The incidence of both diseases was higher on the Czech side of the border. For LB, we did not observe distinct foci, but the incidence decreased sharply on crossing to the Polish side. In case of TBE we observed the continuation of the most intensive foci present on the Czech side to the Polish territory, with important decrease in incidence on the border. Risk ratios between north-eastern and south-western zones in both CZ and PL show a similar gradient decreasing TBE incidence to the north-east. However, within each country it was much smaller than the incidence gradient across the border and the difference between the countries persisted even after adjusting for the north-east gradient (Table 2). This strongly suggests that substantial part of the difference between CZ and PL could be attributed to the uneven performance of the surveillance systems. Additionally, surveillance on the Czech side followed the observed increasing trend of TBE incidence in Europe (11, $21,22)$, which could not be observed on the Polish side.

The real disease occurence is influenced by many factors, however, the causal agents and vectors are the same. A real difference between CZ and PL could still be attributed to differences in environmental and population characteristics. We assumed that host animals, vegetation, altitude, and climatic conditions on both sides of the border are comparable. Taking into consideration the recently discussed role of socio-economic factors as behavioural determinants increasing the risk of tickborne diseases, possible diversity in socio-economic conditions amongst cross-border populations could explain the differences in reported incidence of the diseases (23). Nevertheless, this explanation seems unlikely for such large differences in tick-borne disease occurrence, since both populations are similar in terms of language, culture, and socio-economic standing. Moreover, in the Czech Republic an analysis of socio-economic conditions in high-risk areas for TBE has not revealed any impact of these conditions on TBE morbidity (22). During the analyzed period, 40-60 million people were crossing the Czech-Polish border each year (17), which was mostly related to the local traffic for transborder shopping and tourism. Considerable part of strict border zones in both countries is covered by forests and low mountains, and there are very popular tourist destinations on both sides. Only one natural barrier, the Krkonoše mountains, extending on 50 $\mathrm{km}$ of the Czech-Polish border (max. altitude 1,602 metres) can constitute a barrier for tick activity (24). To address differences in urbanization of the two cross-border areas, we adjusted the results to the population density in the examined regions. The observed cross-border surveillance gradient cannot be related to different TBE immunization policies either. Interestingly, a much higher reported immunization coverage for TBE vaccine in CZ (11\%, vs. $0.8 \%$ in Poland) $(25,26)$ should rather produce an opposite effect with decreased TBE incidence in CZ.

The possible reasons for the detected considerable differences in surveillance performance between the two countries can be potentially linked to underreporting of diagnosed cases and/or to missed diagnoses, due to lack of laboratory testing. First, despite a similar historical structure, the public health surveillance systems in CZ and in PL were managed differently during the recent decades. Historically, in CZ only persons with medical degree were allowed to work with medical documentation in the local Public Health Departments. They could communicate more efficiently with reporting physicians, educating them on changing surveillance guidelines and diagnostic procedures. Also, the National Institute of Public Health in Prague was instrumental in strengthening surveillance as well as using surveillance for ongoing revision of diagnostic and preventive guidelines (27). 
The situation has changed in recent years, and non-MD specialists are recruited increasingly as public health officers. In Poland most of the employees working in communicable disease surveillance at the local level were lacking university education and experienced problems in addressing public health messages to reporting physicians. Second, both tick-borne diseases were included as mandatory notifiable entities for a longer time in CZ allowing physicians to familiarize with the reporting requirements. The recent introduction of LB as notifiable disease in PL (1999) could explain the decreasing incidence gradient between the two countries as the surveillance of LB in Poland was systematically improving (Fig. 2, Table 3). Third, Polish physicians could refer less commonly suspect tick-borne disease cases for diagnosis. Healthcare reforms, started in 1999, consisted of healthcare system decentralization and reorganization of the reimbursement of medical procedures. Following the implementation of the reforms, a substantial decrease in availability of diagnostic procedures was observed, including the microbiological tests used for confirmation of communicable diseases, especially if clinical management is not changed as a result of microbiological diagnosis $(28,29)$. Fourth, Polish physicians, less numerous than in CZ (Table 1), were found to be reluctant to report infectious disease cases due to significant work load (30).

The presented method of surveillance systems comparison has several limitations. Because TBE foci can be limited to very small areas, the incidence gradient should be evaluated using the highest possible resolution. In the present study we used the lowest administrative level (Eurostat NUTS4) for which data were available in both countries. Should more detailed data be easily available, GIS techniques could be employed using point-mapped exposure sites of reported cases. Also specificity and predictive positive values of both surveillance systems can differ, which would necessitate more in-depth analyses. Despite these limitations, the presented approach provides insight into how well the surveillance systems are able to measure the disease incidence and consequently burden of illness in neighbouring areas, and allows discussion on the potential reasons of observed differences.

Our results indicate large differences in the crude incidence of TBE and LB between two neighbouring regions in the Czech Republic and Poland. The high incidence gradient on the CZ/ PL border persisted when adjusting for natural disease gradient within both countries, and for population density. Those results reflect possible differences in surveillance systems performance between the two countries, as the administrative boundaries cannot constitute a barrier for zoonotic diseases and no biological processes alone can explain such large differences in disease occurrence. Such important differences in surveillance performance may impact the ability of the surveillance systems to monitor disease trends, and to plan public health interventions. For example, good quality data on TBE risk areas available at the international level are key prerequisite for development of travel vaccine recommendations (26). Better insight into surveillance systems performance is especially important in the time of globalization, when available surveillance figures are increasingly compared between countries. Therefore, we recommend cautious comparison of communicable diseases burden between countries. These comparisons should be accompanied by underreporting estimates as well as in-depth understanding of the organization of surveillance systems, methods of data collection, and data flow.
However, we show that even similarly structured surveillance systems can provide incomparable output drawing attention to health care system differences.

\section{Acknowledgement}

We would like to acknowledge Justyna Rogalska and Aleksandra Turczyńska for their contribution in maintenance of the tick-borne diseases databases as well as James Stuart and Anna Zielicka-Hardy for their useful comments on the manuscript.

\section{Conflict of Interests}

None declared

\section{REFERENCES}

1. Thacker SB. Historical development. In: Teutsch SM, Churchill RE, editors. Principles and practice of public health surveillance. 2nd ed. Oxford: Oxford University Press; 2000.

2. Thiemann C, Theis F, Grady D, Brune R, Brockmann D. The structure of borders in a small world. PLoS One. 2010 Nov 18;5(11):e15422.

3. Su D, Richardson C, Wen M, Pagán JA. Cross-border utilization of health care: evidence from a population-based study in south Texas. Health Serv Res. 2011 Jun;46(3):859-76.

4. Grier NL, Homish GG, Rowe DW, Barrick C. Promoting information sharing for multijurisdictional public health emergency preparedness. J Public Health Manag Pract. 2011 Jan-Feb;17(1):84-9.

5. European Commission. Commission Decision of 19 March 2002 laying down case definitions for reporting communicable diseases to the Community network under Decision No 2119/98/EC of the European Parliament and of the Council: (notified under document number C(2002) 1043): (2002/253/EC). Official Journal of the European Communities. 2002 Apr 3;45(L86):44-62.

6. Amato-Gauci A, Zeller H. Tick-borne encephalitis joins the diseases under surveillance in the European Union. Euro Surveill. 2012 Oct 18;17(42). pii: 20299.

7. Trotter C, Samuelsson S, Perrocheau A, de Greeff S, de Melker H, Heuberger $\mathrm{S}$, et al. Ascertainment of meningococcal disease in Europe. Euro Surveill. 2005 Dec;10(12). pii: 586.

8. Hanquet G, Perrocheau A, Kissling E, Bruhl DL, Tarragó D, Stuart J, et al.; ECDC Country Experts for Pneumococcal Disease. Surveillance of invasive pneumococcal disease in $30 \mathrm{EU}$ countries: Towards a European system? Vaccine. 2010 May 21;28(23):3920-8.

9. Stańczak J, Racewicz M, Kubica-Biernat B, Kruminis-Lozowska W, Dabrowski J, Adamczyk A, et al. Prevalence of Borrelia burgdorferi sensu lato in Ixodes ricinus ticks (Acari, Ixodidae) in different Polish woodlands. Ann Agric Environ Med. 1999;6(2):127-32.

10. Stefanoff P, Rosińska M, Zieliński A. Epidemiology of tick-borne diseases in Poland. Przegl Epidemiol. 2006;60 Suppl 1:151-9. (In Polish.)

11. Kriz B, Maly M, Benes C, Daniel M. Epidemiology of tick-borne encephalitis in the Czech Republic 1970-2008. Vector Borne Zoonotic Dis. 2012 Nov;12(11):994-9.

12. Danielová V, Daniel M, Rudenko N, Golovchenko M. Prevalence of Borrelia burgdorferi sensu lato genospecies in host-seeking Ixodes ricinus ticks in selected South Bohemian locations (Czech Republic). Cent Eur J Public Health. 2004 Sep;12(3):151-6.

13. Zeman P, Januska J. Epizootiologic background of dissimilar distribution of human cases of Lyme borreliosis and tick-borne encephalitis in a joint endemic area. Comp Immunol Microbiol Infect Dis. 1999 Oct;22(4):24760.

14. Deguen S, Lalloue B, Bard D, Havard S, Arveiler D, Zmirou-Navier D. A small-area ecologic study of myocardial infarction, neighborhood deprivation, and sex: a Bayesian modeling approach. Epidemiology. 2010 Jul;21(4):459-66.

15. Tu SP, Li L, Tsai JHC, Yip MP, Terasaki G, Teh C, et al. A cross-border comparison of hepatitis B testing among Chinese residing in Canada and the United States. Asian Pac J Cancer Prev. 2009 Jul-Sep;10(3):483-90.

16. Czech Statistical Office. Demographic yearbook of the regions of the Czech Republic 1999 - 2008 [Internet]. Prague: CZSO; 2009 [cited 2014 Mar 5]. Available from: http://www.czso.cz/csu/2009edicniplan. nsf/engpubl/4027-09-1999__2008. 
17. Local Data Bank [Internet]. Warsaw: Central Statistical Office; c19952014 [cited 2014 Mar 5]. Available from: http://www.stat.gov.pl/bdlen/ app/strona.html?p_name=indeks.

18. National Institute of Public Health - National Institute of Hygiene. Department of Epidemiology, Laboratory of Monitoring and Epidemiological Analysis [Internet]. Warsaw: NIPH - NIH [cited 2014 Mar 5]. Available from: http://www.pzh.gov.pl/oldpage/epimeld/index_a.html\#01.

19. National Institute of Public Health. Infections in the Czech Republic EPIDAT [Internet]. Prague: NIPH [cited 2014 Mar 5]. Available from: http://www.szu.cz/publikace/data/infekce-v-cr. (In Czech.)

20. National Institute of Public Health. Zprávy Centra epidemiologie a mikrobiologie [Internet]. Prague: NIPH [cited 2014 Mar 5]. Available from: http://www.szu.cz/publikace/zpravy-epidemiologie-a-mikrobiologie. (In Czech.)

21. Donoso Mantke O, Schädler R, Niedrig M. A survey on cases of tick-borne encephalitis in European countries. Euro Surveill. 2008 Apr 24;13(17). pii: 18848 .

22. Daniel M, Beneš Č, Danielová V, Kř́ž B. Sixty years of research of tick-borne encephalitis - a basis of the current knowledge of the epidemiological situation in Central Europe. Epidemiol Mikrobiol Imunol. 2011 Nov;60(4):135-55.

23. Randolph SE; EDEN-TBD sub-project team. Human activities predominate in determining changing incidence of tick-borne encephalitis in Europe. Euro Surveill. 2010 Jul 8;15(27). pii: 19606.

24. Materna J, Daniel M, Danielová V. Altitudinal distribution limit of the tick Ixodes ricinus shifted considerably towards higher altitudes in centra Europe: results of three years monitoring in the Krkonose Mts. (Czech Republic). Cent Eur J Public Health. 2005 Mar;13(1):24-8.
25. Heinz FX, Holzmann H, Essl A, Kundi M. Field effectiveness of vaccination against tick-borne encephalitis. Vaccine. 2007 Oct 23;25(43):755967.

26. Stefanoff P, Polkowska A, Giambi C, Levy-Bruhl D, O'Flanagan D, Dematte L, et al.; VENICE project gatekeepers, contact persons group. Reliable surveillance of tick-borne encephalitis in European countries is necessary to improve the quality of vaccine recommendations. Vaccine. 2011 Feb 1;29(6):1283-8.

27. Rosický B, Minár J. The role of the National Institute of Public Health in the field of infections with natural focality. Cent Eur J Public Health. 1996 May;4(2):123-6.

28. Seifert B, Rubin G, de Wit N, Lionis C, Hall N, Hungin P, et al. The management of common gastrointestinal disorders in general practice A survey by the European Society for Primary Care Gastroenterology (ESPCG) in six European countries. Dig Liver Dis. 2008 Aug;40(8):65966.

29. Stefanoff P, Rogalska J, Zajkowska J, Czerska M, Seroka W, Czarkowski MP. Surveillance of aseptic central nervous system infections in Poland: is it meeting its objectives? Euro Surveill. 2011 Jul 21;16(29). pii: 19924.

30. Kacperczyk-Baran T. Research results on sensitivity of surveillance on the infectious diseases of PSSE Zwoleń. Przegl Epidemiol. 2006;60(2):20511. (In Polish.) 